\title{
Carrier Current Line Systems Technologies in M2M Architecture for Wireless Communication
}

\author{
Hua-Ching Chen, ${ }^{1}$ Chia-Lun Wu, ${ }^{1}$ Jwo-Shiun Sun, ${ }^{2}$ and Hsuan-Ming Feng ${ }^{2}$ \\ ${ }^{1}$ Department of Computer Science and Information Engineering, National Quemoy University, No. 1, Daxue Road, Jinning Towenship, \\ Kinmen 892, Taiwan \\ ${ }^{2}$ Department of Electronic Engineering, National Taipei University of Technology, No. 1, Section 3, Zhongxiao E. Road, \\ Taipei 10608, Taiwan
}

Correspondence should be addressed to Hsuan-Ming Feng; hmfeng@nqu.edu.tw

Received 15 November 2014; Accepted 7 February 2015

Academic Editor: Guiyun Tian

Copyright (C) 2016 Hua-Ching Chen et al. This is an open access article distributed under the Creative Commons Attribution License, which permits unrestricted use, distribution, and reproduction in any medium, provided the original work is properly cited.

\begin{abstract}
This paper investigates the Carrier Current Line Systems (CCLS) technologies of Machine to Machine (M2M) architecture which applied for mobile station coverage working with metro, high speed railway, and subway such as analysis for public transport of an indoor transition system. It is based on the theory and practical engineering principle which provide guidelines and formulas for link budget design to help designers fully control and analyze the single output power of uplink and downlink between Fiber Repeaters (FR) and mobile station as well as base station. Finally, the results of this leakage cable system are successfully applied to indoor coverage design for metro rapid transit system which are easily installed cellular over fiber solutions for WCDMA/LTE access is becoming Ubiquitous Network to Internet of Thing (IOT) real case hierarchy of telecommunication.
\end{abstract}

\section{Introduction}

This paper investigates the CCLS which are applied to radio frequency (RF) over CCLS technologies of M2M architecture for wireless communication based on telecommunication certification body (TCB) workshop Santa Clara, CA, Steve Martin office of engineering and technology equipment authorization Branch Federal Communications Commission (FCC) laboratory, in which CCLS rules are applicable to Radio Over Fiber (ROF) [1, 2] and can access devices operating from $700 \mathrm{MHz}$ to $2100 \mathrm{MHz}[3,4]$.

The definition of CCLS includes use of the transmission line between substation and customer terminal device. CCLS are a part of systems that transmits RF energy by conduction or radiation [5]. CCLS convergence is a trend that fits right in with wireless communication adoption and the benefits of modularization and interoperability. CCLS infrastructure can easily solve the performance, reliability, and compatibility of these systems which operators believe will improve transmission questions. Small pico cell environments with low capital costs and low risk allow operators to try these systems. Rather than using them in a large macroenvironment that would gobble up significant amounts of money as well as increase risk, operators see the advantage of a carrier current line systems.

ROF convergence is a trend that fits right in with wireless communication adoption and the benefits of modularization and interoperability. ROF infrastructure can easily solve the performance, reliability, and compatibility of these systems which operators believe will improve transmission questions.

This paper is organized as follows. The design rules of carrier current line systems are illustrated in Section 2. Then studies of the key factors and solution of the fiber repeater will be discussed in Sections 3 and 4, respectively. Finally, the conclusion is made in Section 5.

\section{Design Rules of Carrier Current Line Systems}

2.1. Basic Theory. The RF over CCLS concepts of FR operation principle are shown in Figure 1. FR is basically divided into two parts. The first part is Main Optical Unit (MOU). 


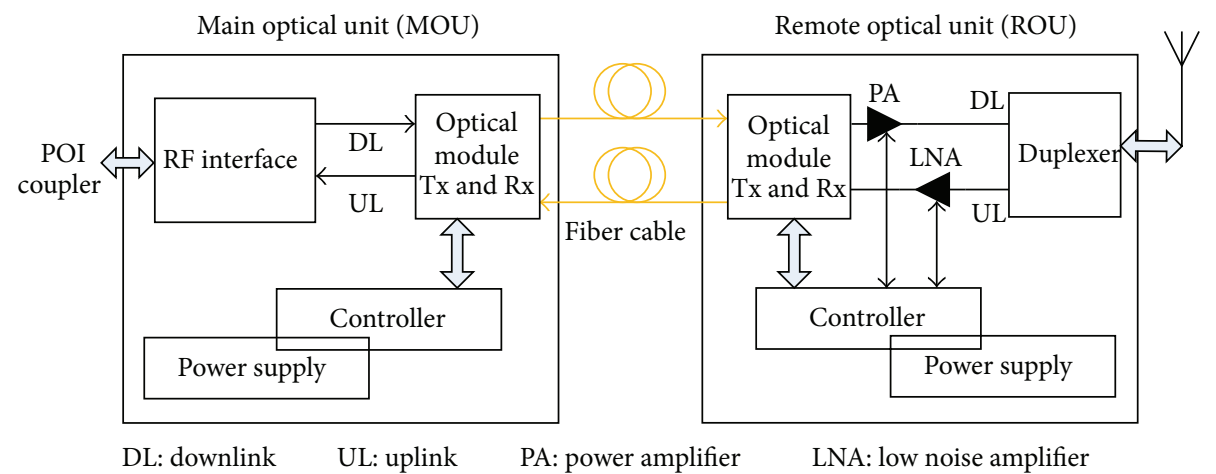

FIGURE 1: A CCLS system block diagram.

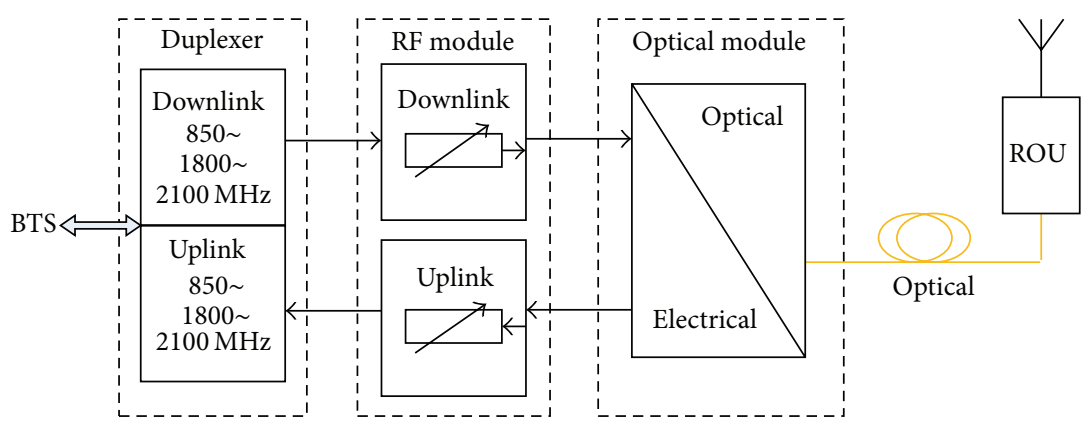

FigUre 2: MOU block diagram.

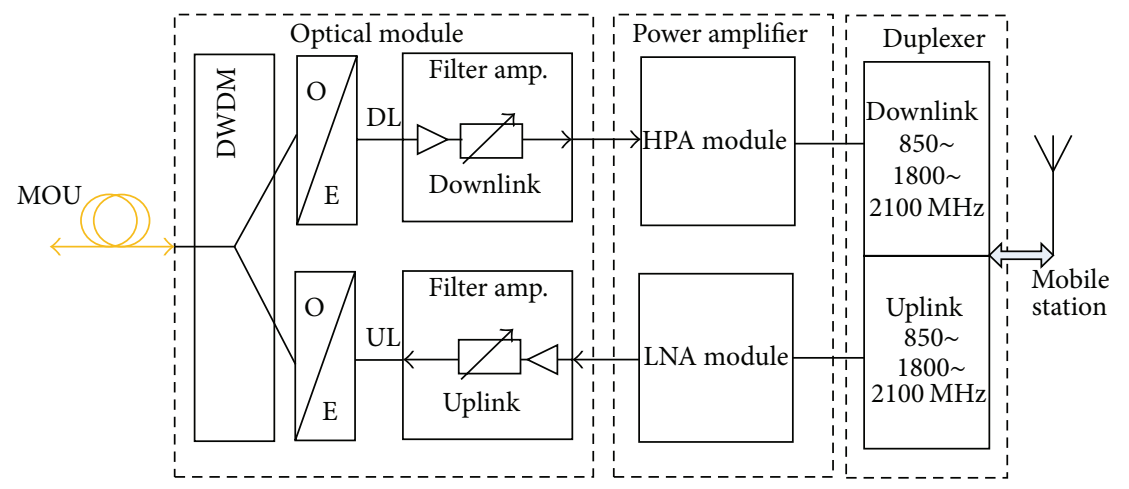

FIgURE 3: ROU block diagram.

MOU converts RF signals in downlink (DL) to optical signals and converts optical signals to RF signals in uplink (UL). The second part is remote optical unit (ROU), which detects DL signals and modulates UL signals.

The MOU [6] system block diagram is illustrated in Figure 2. Because the RF signals coming from the Base Transceiver Station (BTS) in DL are approximately $+13 \mathrm{dBm}$ [7]; the signal level would be attenuated for E/O module receiving. The optical signals are separated into multichannel signals by ROUs. Therefore, the $\mathrm{RF}_{\mathrm{DL}}$ module is composed of adjustable digital attenuator and splitter.

When MOU receives optical signals from ROU through $\mathrm{O} / \mathrm{E}$ optical modules, the RF signal conversions are processed in UL RF modules. Therefore, the RF module is composed of an adjustable digital attenuator and combiner. It distributes the UL signals power which is an attenuated RF signal level in BTS noise floor $\leqq-121 \mathrm{dBm}$. Because BTS services a lot of mobile stations, input noise signal, which is above $-121 \mathrm{dBm}$, will block communication of weak signal cellular phones and drop calls rating.

The ROU [8] block diagram is shown in Figure 3, the remote optical unit in a wireless terminal serves the mobile station (MS).

In the part of $\mathrm{DL}$, the $\mathrm{O} / \mathrm{E}$ module of ROU receives optical signal from the MOU and converts the optical signal into RF signal. Then the RF signal is amplified by power amplifier and transmitted through the antenna. So the basic DL architecture of ROU is the combination of O/E module, IF filtering high frequency conversion module, and power amplifier module. As the same principle, in the part of UL, 
TABLE 1: The calculation of link budget parameter.

\begin{tabular}{|c|c|c|c|c|c|}
\hline \multicolumn{6}{|c|}{ The calculation of link budget parameter } \\
\hline $\mathrm{M} 2 \mathrm{M}$ & $\begin{array}{l}\text { Noise figure NF } \\
\text { (dB) }\end{array}$ & $\begin{array}{l}\text { Signal to Noise } \\
\text { ratio } S / N_{\min } \\
\text { (dB) }\end{array}$ & $\begin{array}{l}\text { Noise floor } N_{\min } \\
\quad(\mathrm{dBm})\end{array}$ & $\begin{array}{c}\text { Sensitivity } S \\
(\mathrm{dBm})\end{array}$ & $\begin{array}{l}\text { Output power } \\
P_{0}(\mathrm{dBm})\end{array}$ \\
\hline BTS & 10 & 9 & -121 & -102 & 44 \\
\hline MS & 12 & 9 & -121 & -100 & 30 \\
\hline
\end{tabular}

mobile station signal is received by the ROU antenna and then modulated to optical signal via another independent fiber back to the MOU, and then the MOU functions of UL of the optical signal from $\mathrm{O} / \mathrm{E}$ module convert into RF signal back to the base station. So, the basic UL architecture of ROU is combination of low noise amplifier module, IF filtering, frequency conversion module, and $\mathrm{O} / \mathrm{E}$ module.

2.2. Canalization of Link Budget. After the above discussion we can understand the impact of the UL output power of two factors: noise figure and MS output power. When the FR gain control settings are better than path loss, FR noise figure for the BTS is relatively small; if on this basis, then leave about $10 \mathrm{~dB}$ of margin; FR to the BTS on effect will be less than $0.3 \mathrm{~dB}$. Select the smallest possible noise figure FR. Reasonable adjustments of the gain of FR and efficiently control the transmitter power of FR. Therefore, to avoid the UL noise brought to the network adverse impact.

(1) Path Loss. Friis free space equation [9] can be written as

$$
P_{r}(d)=\frac{P_{t} G_{t} G_{r} \lambda^{2}}{(4 \pi)^{2} d^{2} L},
$$

where, $P_{r}(d)$ is the transmitter antenna and the distance $d$ is the reception power of the receiver. $P_{t}$ is transmitter power. $G_{t}$ is transmitter antenna gain. $G_{r}$ is receiver antenna gain. $\lambda$ is wavelength of the signal. $d$ is transmitter and receiver distance. $L$ is system loss factor.

Based on the Fraunhofer distance [10], can be written as

$$
d_{f}=\frac{2 D^{2}}{\lambda^{2}}
$$

where $D$ is the maximum size of the antenna. $d_{f}$ is Fraunhofer distance; $d_{f}$ must meet the following two conditions:

$d_{f}>D, d_{f}>\lambda$, and the propagation mode in the Large Scale reception power of the distance $d_{0}$.

$d>d_{0}>d_{f}, P_{r}\left(d_{0}\right)$, and the predicted point than the distance $d$ is the reception power $P_{r}(d)=$ $P_{r}\left(d_{0}\right)\left(d_{0} / d\right)^{2}$.

When they meet the conditions set, see the following formula:

$$
P_{r}(d) \mathrm{dBm}=P\left(d_{0}\right)+20 \log \left(\frac{d_{0}}{d}\right) .
$$

(2) Link Budget between BTS and MS. The calculation of link budget parameter is as shown in Table 1.
BTS and MS sensitivity $(S)$ is the minimum noise floor $\left(N_{\min }\right)$ and noise figure (NF) and minimum Signal to Noise ratio $(S / N)$ min. The sum can be expressed as below:

$$
S=N_{\min }+\mathrm{NF}+\left(\frac{S}{N}\right) \min .
$$

At least of working on service in a telecommunication field the maximum RF uplink path loss signal can be written as

$$
\mathrm{PL}_{\mathrm{UL}, \max }=P_{\mathrm{O} . \mathrm{MS}}-S_{\mathrm{BTS}}
$$

where $\mathrm{PL}_{\mathrm{UL}, \max }$ is maximum $\mathrm{RF}$ uplink path loss signal. $P_{\mathrm{O} \text {.MS }}$ is output power of the MS. $S_{\mathrm{BTS}}$ is the sensitivity of BTS.

The maximum RF DL path loss signal can be written as

$$
\mathrm{PL}_{\mathrm{DL}, \max }=P_{\mathrm{O} . \mathrm{BTS}}-S_{\mathrm{MS}}
$$

where $\mathrm{PL}_{\mathrm{DL} \text {,max }}$ is the maximum downlink path loss. $P_{\mathrm{O} \text {.BTS }}$ is BTS output power. $S_{\mathrm{MS}}$ is mobile station sensitivity.

Therefore, the most path loss in discrepancy of the bidirection imbalance (Imb) can be expressed as

$$
\mathrm{Imb}=\mathrm{PL}_{\mathrm{DL}, \max }-\mathrm{PL}_{\mathrm{UL}, \max } .
$$

According to the standard of IS95 Technical Specification is divided in a calculation of link budget processing:

(1) Find out the sensitivity of BTS and MS:

$$
\begin{aligned}
& S_{\mathrm{BTS}}=(-121 \mathrm{dBm})+10 \mathrm{~dB}+9 \mathrm{~dB}=-102 \mathrm{dBm} \\
& S_{\mathrm{MS}}=(-121 \mathrm{dBm})+12 \mathrm{~dB}+9 \mathrm{~dB}=-100 \mathrm{dBm} .
\end{aligned}
$$

(2) Find the maximum RF uplink path loss signal, $\mathrm{PL}_{\mathrm{UL}, \max }$ :

$$
\begin{aligned}
& \mathrm{PL}_{\mathrm{UL}, \max }=P_{\mathrm{O} . \mathrm{MS}}-S_{\mathrm{BTS}}=44 \mathrm{dBm}-(-100 \mathrm{dBm}) \\
& =144 \mathrm{~dB} .
\end{aligned}
$$

(3) Find the maximum RF downlink path loss signal, $\mathrm{PL}_{\mathrm{DL}, \max }$ :

$$
\begin{aligned}
& \mathrm{PL}_{\mathrm{DL}, \max }=P_{\mathrm{O} . \mathrm{BTS}}-S_{\mathrm{MS}}=30 \mathrm{dBm}-(-102 \mathrm{dBm}) \\
& =132 \mathrm{~dB} .
\end{aligned}
$$

(4) Find the most path loss in discrepancy of bidirection, Imb:

$\mathrm{Imb}=\mathrm{PL}_{\mathrm{DL}, \max }-\mathrm{PL}_{\mathrm{UL}, \max }=144 \mathrm{~dB}-132 \mathrm{~dB}=$ $12 \mathrm{~dB}$.

Obviously, it is uneven in the most path loss of two directions, if one wants to adjust the DL output power of the higher, there is more uneven production that will be very obvious at this moment, so it is not a great help to the system equilibrium that the DL output power is heightened. 


\section{Studies of the Key Factors}

In a cellular communication M2M system between BTS and MS, an added FR thermal noise signal brings BTS to reduce receiving sensitivity.

3.1. Calculation Gain of a Fiber Repeater. The use of a FR in a wireless communication network causes leveling on BTS from which the FR receives the RF signal. In uplink a high interfering signal power at the BTS receiver will cause a service restriction on the MS that is able to transmit a signal whose power will guarantee the required $E_{b} / N_{0}$, where $E_{b}$ is energy bit and $N_{0}$ is spectral noise density. In DL this effect will cause the same problem to the MS receiver. The thermal noise power, $P_{\mathrm{th}}$, can be expressed as

$$
P_{\mathrm{th}}=10 \log [K T B],
$$

where $K$ is Boltzmann's constant $\left(1.38 \times 10^{-23} \mathrm{~J} / \mathrm{K}\right) . T$ is absolute temperature $\left(290^{\circ} \mathrm{K}\right) . B$ is signal bandwidth (200 KHz/Channel).

The thermal noise power of the BTS receiver can be expressed as

$$
P_{\text {th }}=10 \log [K T B]+\mathrm{NF}_{\mathrm{bts}},
$$

where $\mathrm{NF}_{\mathrm{bts}}$ is noise figure of the BTS $(2 \mathrm{~dB}) . P_{\mathrm{bts}}$ is thermal noise power; $P_{\mathrm{bts}}=10 \log [K T B]+\mathrm{NF}_{\mathrm{bts}}=-121 \mathrm{dBm} / \mathrm{Hz}+$ $2 \mathrm{~dB}=-119 \mathrm{dBm}$.

When injected by the FR optical link in correspondence with power sources from BTS, the thermal noise power that BTS receives is the noise figure of the BTS receiver $P_{\mathrm{bts}}$ and thermal noise power of the FR.

3.2. Injected by Fiber Repeater of BTS Deviation. In UL, a high interfering signal power at the BTS receiver will cause a service restriction to the $\mathrm{MS}_{s}$ that is able to transmit a signal whose power will guarantee the required $E_{b} / N_{0}$. In particular, the FR which is an active component that will amplify the signals coming from transmission interfering signal due to thermal noise power. Therefore, the output noise power of FR, $P_{\text {rep }}$, can be expressed as

$$
P_{\text {rep }}=10 \log [K T B]+P_{\text {bts }}+\mathrm{NF}_{\text {rep }}+G_{\text {rep }} \text {, }
$$

where $P_{\text {rep }}$ is thermal noise power of the FR. $P_{\mathrm{bts}}$ is thermal noise power of the BTS receiver. $\mathrm{NF}_{\text {rep }}$ is noise figure of the FR. $G_{\text {rep }}$ is gain of the FR. All of the path loss from BTS to FR is Lp. Therefore, the thermal noise power signal injected by the FR due to BTS receiver, $P_{\text {rep }}^{\prime}$, can be written as

$$
\begin{aligned}
P_{\text {rep }}^{\prime} & =P_{\text {rep }}-\mathrm{Lp} \\
& =10 \log [K T B]+P_{\text {bts }}+\mathrm{NF}_{\text {rep }}+G_{\text {rep }}-\mathrm{Lp} \\
& =119+\mathrm{NF}_{\text {rep }}+G_{\text {rep }}-\mathrm{Lp} .
\end{aligned}
$$

When FR is injected in BTS receiver, the total noise power is $P_{\mathrm{bts}}$-total [11] and should be satisfied as

$$
\begin{aligned}
& P_{\mathrm{bts}} \text { - } \text { total } \\
& =P_{\mathrm{bts}}+P_{\text {rep }}^{\prime}=10 \log \left[10 P_{\mathrm{bts}}+10 P_{\text {rep }}^{\prime}\right] \\
& =P_{\mathrm{bts}} \\
& \quad+10 \log \left[1+\frac{10\left(\mathrm{NF}_{\mathrm{rep}}-\mathrm{NF}_{\mathrm{bts}}+G_{\text {rep }}-L_{p}\right)}{10}\right] .
\end{aligned}
$$

Assume that

$$
10 \log \left[1+10^{\left(\mathrm{NF}_{\mathrm{rep}}-\mathrm{NF}_{\mathrm{bts}}+\mathrm{G}_{\mathrm{rep}}-\mathrm{Lp}\right) / 10}\right]=\Delta N_{\mathrm{bts}},
$$

where $P_{\mathrm{bts}}$-total $=P_{\mathrm{bts}}+\Delta N_{\mathrm{bts}}$.

The above analysis can demonstrate that the injected FR in BTS receiver increases the noise power than one without FR. Furthermore, there are many factors that affect noise floor in BTS receiver.

The related parameters include the noise figure of BTS, noise figure of the FR, the gain of FR, and the path loss from BTS to FR. The equation can be written as (13).

When $\mathrm{NF}_{\text {rep }}-\mathrm{NF}_{\mathrm{bts}}+G_{\text {rep }}-L_{p}=0$, then the noise floor has increased $\Delta N_{\text {bts }}$, which equals $3 \mathrm{~dB}$, in receiver port of BTS.

When $\mathrm{NF}_{\text {rep }}-\mathrm{NF}_{\mathrm{bts}}+G_{\text {rep }}-L_{p}=-6$, then the noise floor has increased by $\Delta N_{\mathrm{bts}}$, which equals $0.97 \mathrm{~dB}$, in receiver port of BTS. Therefore, the invaded FR is not an influence on BTS receiver.

In general, the noise figure of $\mathrm{NF}_{\mathrm{bts}}$ is $2 \mathrm{~dB}$. Following (10), the thermal noise power signal injected by the FR due to BTS received $P_{\text {rep }}$ is $-125 \mathrm{dBm}$.

In the engineering practice, the noise figure of BTS and FR is constant, the noise floor increase of BTS receives port, and $\Delta N_{\text {bts }}$ has an influence on the path loss of the BTS transmitter to FR and FR $G_{\text {rep }}$.

The noise figure of BTS, $\mathrm{NF}_{\mathrm{bts}}$, is $2 \mathrm{~dB}$. The noise figure of $\mathrm{FR}, \mathrm{NF}_{\text {rep }}$, is $5 \mathrm{~dB}$ as usual. The gain of FR, $G_{\text {rep }}$, should be lower than $8 \mathrm{~dB}$ path loss. By limiting $G_{\text {rep }}$, the $\Delta N_{\text {bts }}$ would be controlled under $1 \mathrm{~dB}$.

In the network design, if the range of the objective coverage is relatively great, it needs to connect in parallel to a lot of FR. In this case, the noise floor of BTS receiver, $P_{\mathrm{bts}}{ }^{-}$ total, is the noise figure and the thermal noise power signal injected by the FR due to BTS receive port, $P_{\text {rep }}^{\prime}$ is shown to be $P_{\text {rep }}$-total $=10 \log \left[10 P_{\text {bts }}+10\left(P_{\text {rep }}^{\prime}\right)\right]$. The quantity of FR is $n$. In order to control the $P_{\text {rep }}$-total, the $\Delta N_{\text {bts }}$ must be under $1 \mathrm{~dB}$. The BTS noise floor has increased by FR as shown in Table 2.

The $\Delta N_{\text {bts }}$ signal increment by FR due to the BTS receiver is equal. For case of $n \mathrm{FR}_{s}$ injected in BTS receiver, the noise power $P_{\text {rep }}^{\prime}$, contributed by one of $\mathrm{FR}_{s}$, should be followed as $P_{\text {rep }}^{\prime}<-125-10 \log _{n}$.

If every one of the $\mathrm{FR}_{s}$ has the same path loss $L_{p}$, the FR gain in $n \mathrm{FR}_{s}$ is smaller than one in one FR. In $n \mathrm{FR}_{s}$, the dropped value for FR gain is about $10 \log _{n}$. Generally, UL gain of FR is set in BTS receiver by some considerations: 
TABLE 2: The BTS noise floor increased by FR.

\begin{tabular}{ccc}
\hline \multicolumn{3}{c}{ BTS noise floor increased by FR } \\
$10 \log \left[1+n 10^{\left(\mathrm{NF}_{\mathrm{rep}}-\mathrm{NF}_{\mathrm{bts}}-G_{\text {rep }}-\text { PathLoss }\right) / 10}\right] \mathrm{dB}$ \\
$n$ & $(n)=\mathrm{NF}_{\text {rep }}-\mathrm{NF}_{\mathrm{bts}}-G_{\text {rep }}-L_{p}(\mathrm{~dB})$ & $\begin{array}{c}P_{\mathrm{bts}}: \text { the thermal } \\
\text { noise power of BTS } \\
\text { receive }(\mathrm{dB})\end{array}$ \\
\hline 0 & 0 & 3 \\
1 & -6 & 1.77 \\
2 & -9 & 0.98 \\
\hline
\end{tabular}

TABLE 3: The calculation of the link budget fiber repeater.

\begin{tabular}{|c|c|}
\hline \multicolumn{2}{|c|}{ The calculation of the link budget fiber repeater } \\
\hline $\mathrm{UL} G_{\text {rep }}(\mathrm{dB})$ & $\begin{array}{c}\left(L_{p}\right)+\left(\mathrm{NF}_{\mathrm{bts}}\right)-\left(\mathrm{NF}_{\mathrm{rep}}\right)+\Delta N_{\mathrm{bts}}= \\
39+2-5+(-9)=27\end{array}$ \\
\hline $\mathbf{N}$ & $\Delta \mathrm{N}_{\mathrm{bts}}:$ number of fiber repeater (n) \\
\hline 0 & 0 \\
\hline 1 & -6 \\
\hline 2 & -9 \\
\hline $\mathrm{NF}_{\mathrm{bts}}(\mathrm{dB})$ & 2 \\
\hline $\mathrm{NF}_{\text {rep }}(\mathrm{dB})$ & 5 \\
\hline Path loss $\mathrm{L}_{\mathrm{p}}(\mathrm{dB})$ & $\begin{array}{c}\text { Path loss }\left(\mathrm{L}_{\mathrm{p}}\right)=\text { coupling loss }+ \text { cable } \\
\text { loss }+ \text { combiner loss }=39\end{array}$ \\
\hline Coupling loss (dB) & 30 \\
\hline Cable loss (dB) & 2 \\
\hline Combiner loss $(\mathrm{dB})$ & 7 \\
\hline
\end{tabular}

(1) path loss $L_{p}$ from BTS transmitter to FR,

(2) numbers of FR in parallel to BTS receiver.

In general, the FR directly couples to signal, which comes from BTS, and the path loss of FR is $L_{p}$ for the coupling of the coupler. The same principle, UL of FR gains, needs more than a small coupling loss about $8 \mathrm{~dB}$.

It should need two parallel $\mathrm{FR}_{s}$ for practice. In general, choose a high coupling ratio of coupler, when the input optic fiber signal of FR is $0 \mathrm{dBm}$. Therefore, the path loss coming from BTS to FR is $39 \mathrm{~dB}$. The FR of UL gain is $31 \mathrm{~dB}$, so a FR invades the BTS receive port of sensitivity that is not influenced. The calculation of the UL budget of FR is shown in Table 3.

3.3. Link Budget of FR and MS. The implementation of FR of $\mathrm{DL}$ gain is to control the output power of the FR, which has considered between FR and $i$ system equilibrium [12]. For the equilibrium of guaranteeing to UL and DL the transmission power, the FR should be satisfied as

$$
P_{\text {o-rep }}=P_{\text {o-ms }}+\mathrm{NF}_{\mathrm{ms}}-\mathrm{NF}_{\text {rep }} \text {, }
$$

where $P_{\text {o-rep }}$ is FR of output power. $P_{\mathrm{o}-\mathrm{ms}}$ is $\mathrm{MS}$ of output power. $\mathrm{NF}_{\mathrm{ms}}$ is noise figure of $\mathrm{MS} . \mathrm{NF}_{\text {rep }}$ is noise figure of FR. The maximum of the MS output power is $P_{\mathrm{o}-\mathrm{ms}}=33 \mathrm{dBm}$, noise figure of $\mathrm{MS}$ is $\mathrm{NF}_{\mathrm{ms}}=6 \mathrm{~dB}$, and noise figure of $\mathrm{FR}$ is $\mathrm{NF}_{\text {rep }}=5 \mathrm{~dB}$.

Therefore, the maximum FR output power is $P_{\text {o-rep }}=33+$ $6-5=34 \mathrm{dBm}$. Attention should be paid to the DL budget of FR. In the case of FR practical, when implementation of a gain adjustment has been considered, isolation between FR and the antenna prevents FR from local oscillations.

\section{Solution of the Fiber Repeater}

4.1. System Structure and Link Budget. Real case 1: MRT R4$\mathrm{R} 4 \mathrm{~A}$ implement and measurement practices.

(1) Indoor Coverage Requirements and Inspection Methods. Measurements are performed at three different areas having installed with MRT underground environment includes multiservices stations and tunnels of quality [11] plan in indoor coverage requirements and acceptances as in Table 4.

(2) System Structure and Link Budget. The system network structure needs tunnel environment factor and signal objective coverage plan [13] as shown in Figure 4.

(3) Power Spectrum Density of Calculations. R4 to R4A LC is installed at well number four of south and north tunnel is one, respectively, LC connected to ROU output port $[14,15]$. In used to R4 to R4A, for example, as shown in Figure 5 the FR system structure.

R4 Station [R4 to R4A] Control room of POI + MOU $\times 1, N / S$ tunnel intersection exit ROU $\times 2$. Control room, intersection exit and system network plan calculation of link budget $[11,12]$. As shown in Figure 6 System network plan and calculation of link budget of Machine to Machine (M2M) architecture.

\subsubsection{Station R4 to 4A of Power Spectrum Density}

R4 Station. $195 \mathrm{~m}, \mathrm{R} 4$ Station BTS provided R4 to R4A in tunnel signal coverage. Control room to tunnel exit is $181 \mathrm{~m}$, $1-5 / 8^{\prime \prime}$ coaxial cable loss is $8 \mathrm{~dB}$, and tunnel length is $1,600 \mathrm{~m}$.

Intersection. FR of two types of ROU equipment are installed number of the south and north tunnel is one, respectively, Point of Interface (POI) output port connects to MOU. MOU output ports connect fiber cable to intersection ROU input port. R4 to R4A leakage cable is installed at well number three of south and north tunnel is one, respectively, leakage cable connected to ROU output port. In used to R4 to R4A, for example, as shown in Figure 5.

\subsection{2. $R 4$ to $4 A$ in Tunnel of Signal Coverage Canalization}

(1) [R4 Tunnel Exit to inside of Tunnel], [R4A Tunnel Exit to inside of Tunnel], and [POI $+1-5 / 8^{\prime \prime}$ Leakage Cable]. The practical analysis of signal coverage area from POI through 1$5 / 8^{\prime \prime}$ coaxial cable to $N / S$ tunnel intersection exit connected 
TABLE 4: Requirements and acceptances of the quality plan in indoor coverage.

\begin{tabular}{|c|c|c|c|c|c|c|c|}
\hline \multicolumn{8}{|c|}{ Requirements and acceptances of the quality plan in indoor coverage } \\
\hline System & Area A & $\begin{array}{l}\text { Signal } \\
\text { strength } \\
(\mathrm{dBm})\end{array}$ & Area B & Signal strength $(\mathrm{dBm})$ & Area C & $\begin{array}{c}\text { Signal } \\
\text { strength } \\
(\mathrm{dBm})\end{array}$ & $\begin{array}{c}\text { Coverage } \\
(\%)\end{array}$ \\
\hline $\begin{array}{l}\text { DCS } \\
\text { LTE }\end{array}$ & \multirow{3}{*}{$\begin{array}{l}\text { Hall, shopping mall, } \\
\text { information service, } \\
\text { sell ticket area, } \\
\text { electric escalator, and } \\
\text { platform }\end{array}$} & $\geq-75$ & Parking area & $\geq-85$ & $\begin{array}{l}\text { Elevator, control } \\
\text { room, } \\
\text { TRA machine room } \\
\text { toilet, office, and exit } \\
\text { on tunnel }\end{array}$ & $\geq-90$ & $95 \%$ \\
\hline CDMA 2000 & & \multirow{2}{*}{$\geq-80$} & \multirow{2}{*}{\multicolumn{2}{|c|}{ Tunnel and LaBa area }} & & $\geq-85$ & $95 \%$ \\
\hline WCDMA & & & & & & $\geq-90$ & $5 \%$ \\
\hline
\end{tabular}

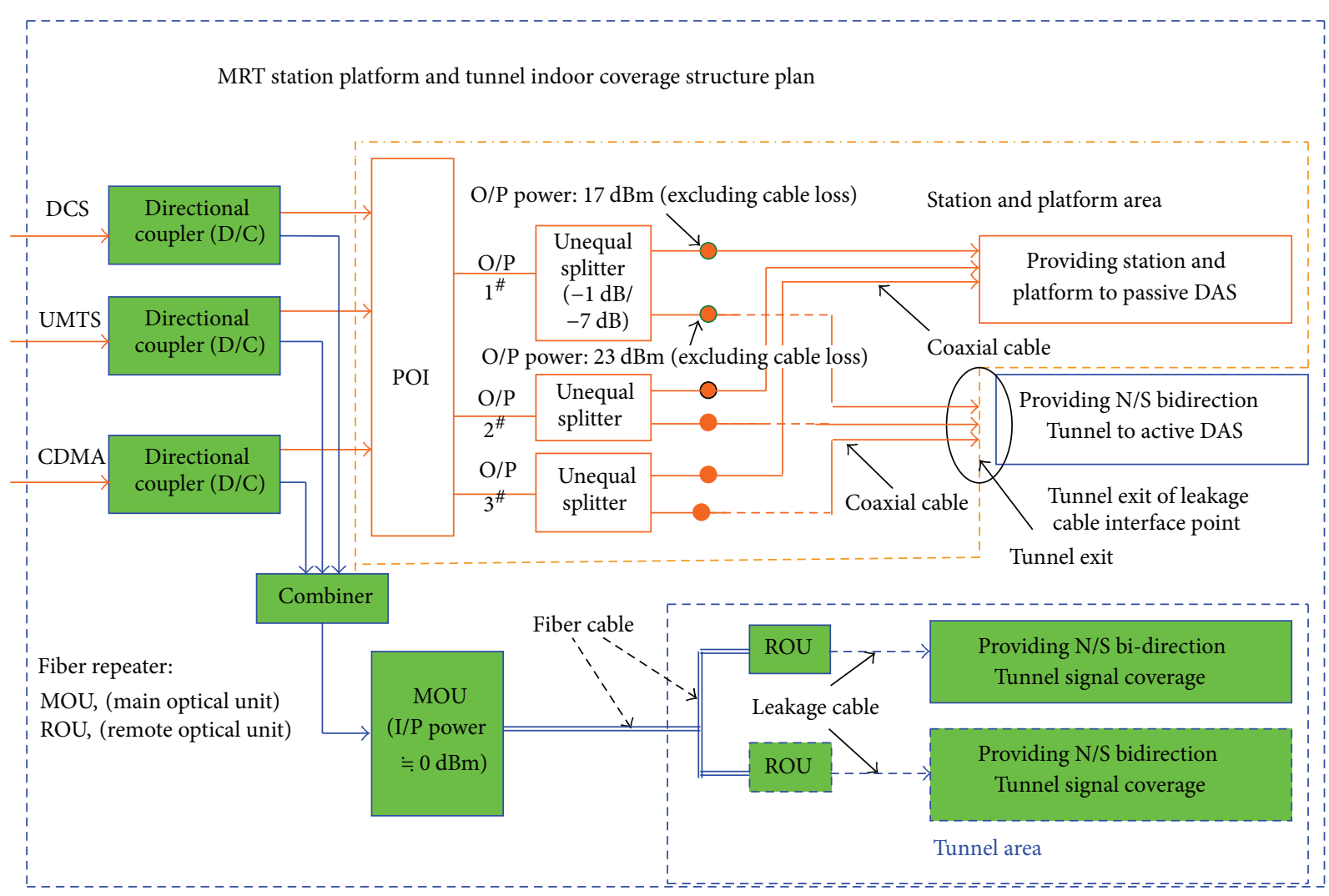

FIGURE 4: The MRT in building coverage of system network architecture.

$1-5 / 8^{\prime \prime}$ leakage cable of equation can be written as (15), (16), and (17). Consider the following:

$$
P_{\mathrm{o}(\mathrm{ROU})}=P_{t(\mathrm{bts})}-L_{\mathrm{POI}}-L_{\mathrm{CC}}
$$

where $P_{\mathrm{o}(\mathrm{ROU})}$ is output power of ROU to leakage cable. $P_{t(\mathrm{bts})}$ is output power of BTS. $L_{\mathrm{POI}}$ is insertion loss of POI. $L_{\mathrm{CC}}$ is coaxial cable loss (about $181 \mathrm{~m}) \cdot P_{\mathrm{o}(\mathrm{ROU})}=33 \mathrm{dBm}-9 \mathrm{~dB}-$ $8 \mathrm{~dB}=16 \mathrm{dBm}:$

$$
L_{\mathrm{TOT}}=P_{\mathrm{o}(\mathrm{ROU})}-\mathrm{SS}_{\mathrm{req}}(\mathrm{dB}) \text {, }
$$

where $L_{\text {TOT }}$ is total of maximum allowed loss. $S_{\text {req }}$ is signal strength requirement $(-85 \mathrm{~dB}) L_{\mathrm{TOT}}(-85 \mathrm{~dB})=16-(-85 \mathrm{~dB})$ $=101 \mathrm{~dB}$ :

$$
L_{\mathrm{LL}}=L_{\mathrm{TOT}}-L_{F}-L_{S}-L_{C}-L_{W}(\mathrm{~dB}),
$$

where $L_{\mathrm{LL}}$ is longitudinal loss. $L_{F}$ is Feeder loss $(5 \mathrm{~dB}) . L_{S}$ is Splitter loss $(3.5 \mathrm{~dB}) . L_{C}$ is coupling loss $(66 \mathrm{~dB}) . L_{W}$ is Window loss $(12 \mathrm{~dB}) ; L_{\mathrm{LL}}=101-5-3.5-62-12=22(\mathrm{~dB})$.

(2) [Intersection Exit to R4 inside of Tunnel] and [Intersection Exit to R4A inside of Tunnel]. The practical analysis of signal 


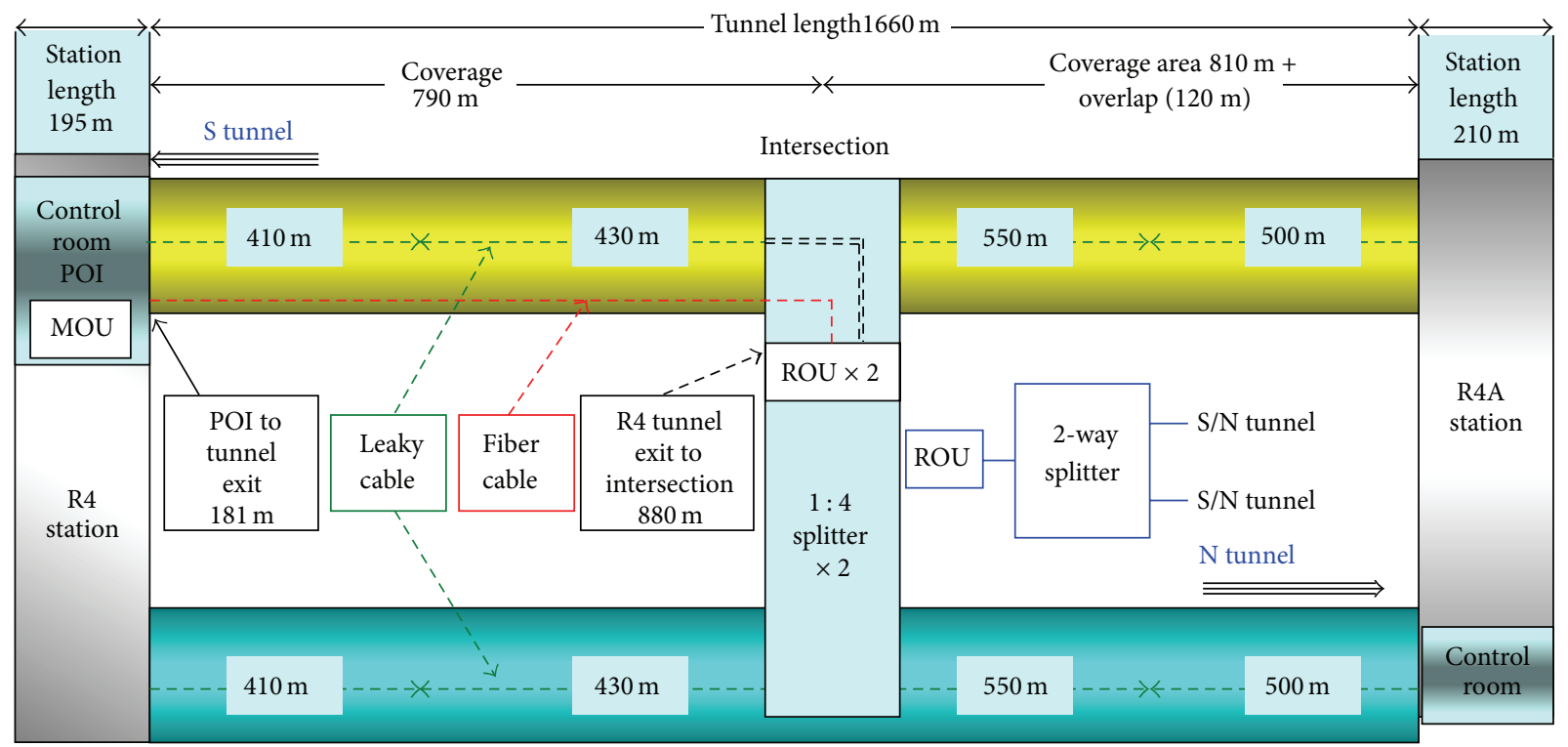

FIGURE 5: The FR system structure.

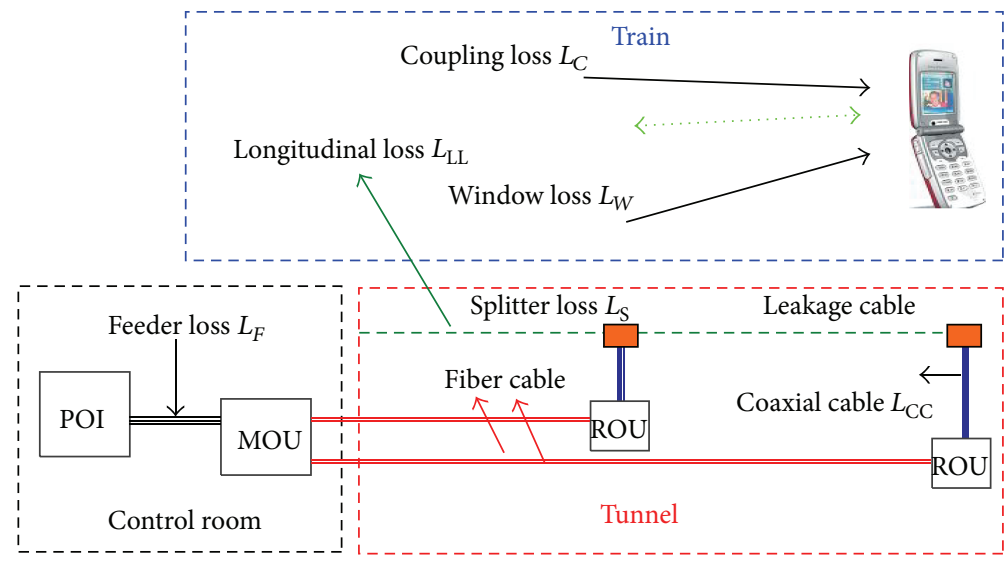

Maximum allowed loss $\left(L_{\mathrm{TOT}}\right) \mathrm{dB}=$ Feeder loss $\left(L_{F}\right)+$ Splitter loss $\left(L_{S}\right)+$ longitudinal loss $\left(L_{\mathrm{LL}}\right)+$ coupling loss $\left(L_{C}\right)+$ Window loss $\left(L_{W}\right)$

Longitudinal loss $\left(L_{\mathrm{LL}}\right) \mathrm{dB}=$ maximum allowed loss $\left(L_{\mathrm{TOT}}\right)-$ Feeder loss $\left(L_{F}\right)-$ Splitter loss $\left(L_{S}\right)-$ coupling loss $\left(L_{C}\right)-$ Window loss $\left(L_{W}\right)$

FIGURE 6: System network plan and calculation of link budget of Machine to Machine (M2M) architecture.

coverage area from intersection exits ROU connected to 1$5 / 8^{\prime \prime}$ leakage cable.

As in (17),

[Intersection exit to R4 inside of tunnel]

$P_{\mathrm{o} \text { (ROU) }}=27 \mathrm{dBm}$, Splitter $\times 2(1: 4) .1-5 / 8^{\prime \prime}$ leakage cable is $480 \mathrm{~m}$;

$L_{\mathrm{TOT}}(-85 \mathrm{~dB})=27-(-85 \mathrm{~dB})=112 \mathrm{~dB} ; L_{\mathrm{LL}}=112-$ $4-7-66-12=23(\mathrm{~dB})$;

[Intersection exit to R4A inside of tunnel] $1-5 / 8^{\prime \prime}$ leakage cable is $600 \mathrm{~m}$;

$L_{\mathrm{LL}}=112-4-1-66-12=29(\mathrm{~dB})$.

\subsubsection{Measurement of the Practice}

(1) System Structure and Quality Plan. The system network structure while need to tunnel environment and signal objective of cell coverage plan as shown in Figure 5 and Table 4.

(2) The Tool of Measurements. The measurement even was conducted using Ericsson Test Mobile System (ETMS). It consists of a HP portable computer, HTC M8 or Samsung Note 3 mobile unit, and the ETMS investigation 8.1 data collection software. A detailed description of ETMS can be found in [16]. Equipped with ETMS, one can measure the 


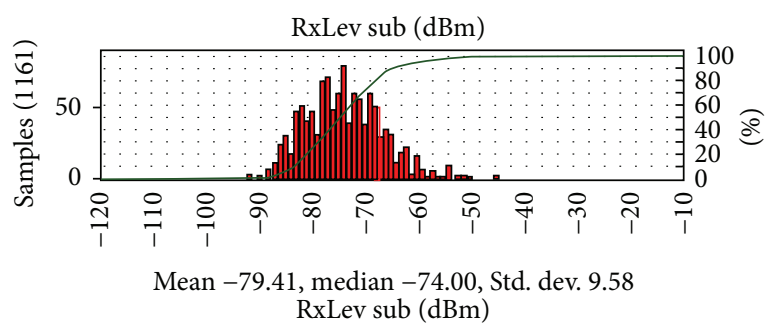

(a)

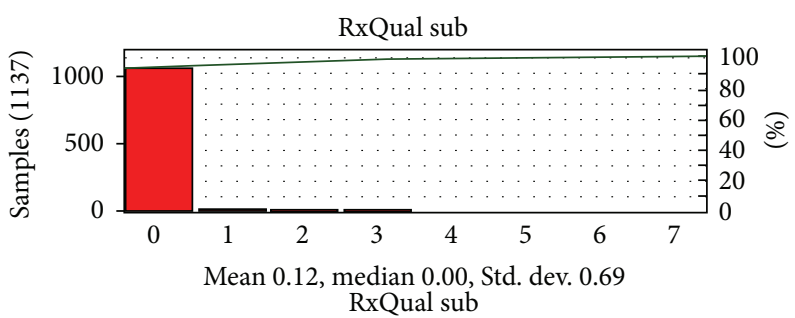

(b)

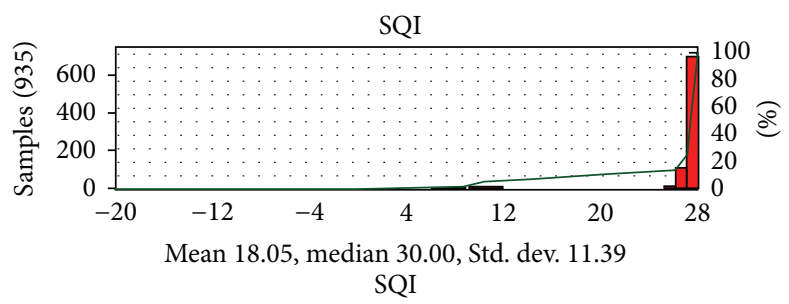

(c)

FIGURE 7: Mobile station of RxLev and RxQual measured walking around the platform.

performance of any DCS, CDMA, and WCDMA mobile communication network [17]. ETMS mobile guarantees the accuracy, mentioned in the 3GPP TS specifications [18], according to which it can measure with absolute accuracy of $\pm 5 \mathrm{~dB}$ from $-105 \mathrm{dBm}$ to $-40 \mathrm{dBm}$ under normal conditions. The dynamic range for measurement of received level is $-110 \mathrm{dBm}$ to $-35 \mathrm{dBm}$. However, in dedicated mode ETMS can measure maximum Rx Level of $-13 \mathrm{dBm}$.

(3) Measurement of the Result. Typical measurements include received signal level, received signal quality, speech quality index, and quality of service. Received signal level (RxLev) in $\mathrm{dBm}$ is used to measure the strength of signal received by the mobile. Received signal quality (RxQual) is directly related to the bit error rate (BER) over the transmission. Speech quality index (SQI) is a parameter to measure the quality of speech. Quality of service (QoS) deals with coverage area, the block probability, and dropped calls of measured quality indicators for DCS network system.

4.1.4. The Part of Station and Platform. RxLev is used to evaluate the signal strength of the DCS system. However, it should be known that a high RxLev recorded may well be due to the presence of high cochannel interference. The signal strength could be especially high if the interference component is in phase with the carrier. Assuming minimal effect from interference, RxLev should be $-75 \mathrm{dBm} \sim-100 \mathrm{dBm}$ for an acceptable quality. As show in Table 5 , it is description the correspondence between RxQual and BER.

MS of RxLev and RxQual measured walking around the platform. As shown in Figure 7 is measured and RxQual RxLev underground R3 station at the second floor of the platform cyclic sampling and measurement analysis [19].

In Figure 7, there are four peaks that occurred in RxLev. This is because test engineers take instruments and walk close to antenna four times. Moreover, it can be seen that there is
TABLE 5: Received signal level and bit error rate conversion table.

\begin{tabular}{lc}
\hline RxQual & BER \\
\hline 0 & Below 0.002 \\
1 & $0.002-0.004$ \\
2 & $0.004-0.008$ \\
3 & $0.008-0.016$ \\
4 & $0.016-0.032$ \\
5 & $0.032-0.064$ \\
6 & $0.064-0.128$ \\
7 & Above 0.128 \\
\hline
\end{tabular}

TABLE 6: SQI ranges and the corresponding speech impression.

\begin{tabular}{lc}
\hline SQI range & Speech impression \\
\hline $21-30$ & Excellent \\
$16-20$ & Good \\
$11-15$ & Acceptable \\
$5-10$ & Bad \\
Below 4 & Not acceptable
\end{tabular}

about $95 \%$ of RxLev, which is larger than $-79.41 \mathrm{dBm}$. In other words, all RxLev values $-85 \leqq x<-65 \mathrm{dBm}$ are above $98.9 \%$. RxQual values remain below 1 and SQI are at 18.05, as shown in Figure 7.

SQI ranges versus the corresponding speech impression are listed in Table 6. SQI should meet at least 16 to 20 calls for good speech impression.

4.1.5. Tunnel. The appearance of five peaks is correlated with the feeding points of leakage cable at MRT five stations. All RxLev values $-76.0 \mathrm{dBm}$ are above $95.9 \%$; all RxQual values are below 1.29 and SQI are 20.89, which are all shown in Figure 8. 


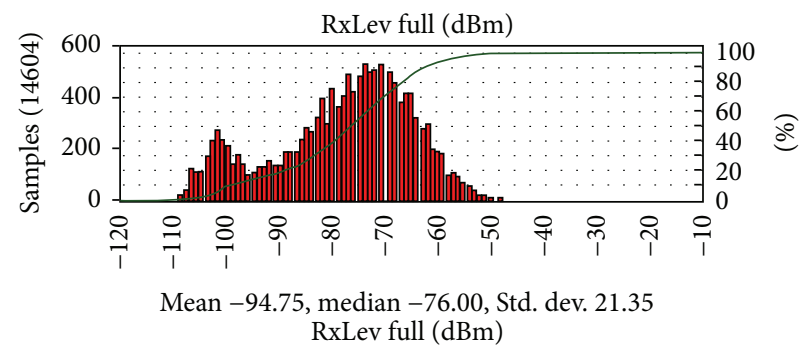

(a)

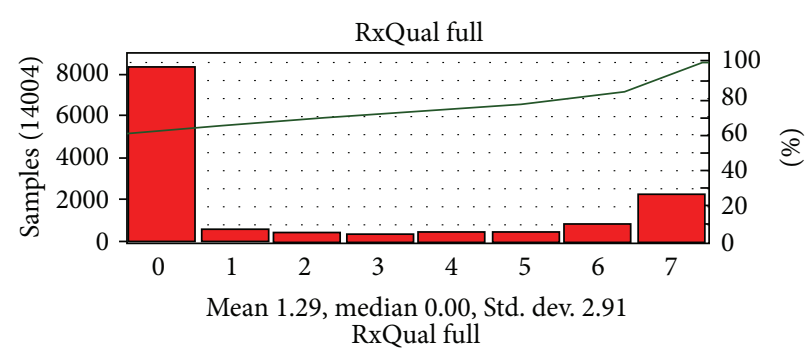

(b)

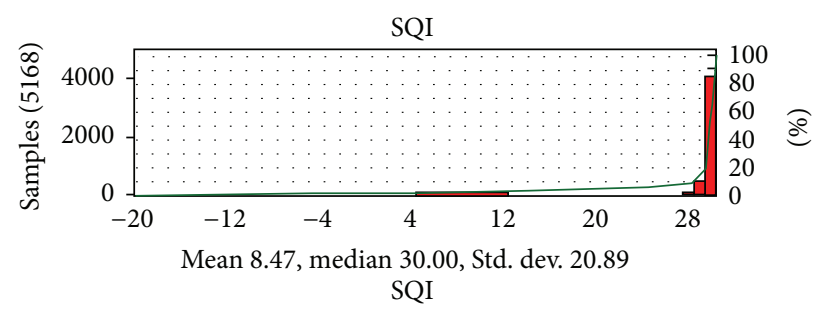

(c)

FIgURE 8: RxLev with RxQual and SQI overview of the tunnel measurement analysis.

The wireless communication system from MRT measure of service quality index coverage, blocking rate, and dropped call rate is the QoS indicators. These results clearly show the mass transit environment and maintain good RxLev SQI with RxQual interrelated data such as the importance of quality of service.

\section{Conclusion}

An achievement of tunnel engineering in indoor coverage for CCLS design engineers and maintenance engineers properly performs planning analysis and maintenance operation based on abovementioned critical points; FR equipment can solve open area of transmission problem for indoor coverage of M2M architecture of wireless communications.

This paper describes in detail FR's importance of design principles, including (a) the calculation of the gain; (b) the calculation of uplink and downlink power balance; (c) indoor coverage which the practice of design and measurement for acceptance procedure.

As long as design engineers and maintenance engineers properly perform planning analysis and maintenance operation based on abovementioned critical points, fiber repeater indeed can solve open area of transmission problem for indoor coverage of mobile communications.

This paper proves a complete practice of design and measurement results for wireless communication network configurations with a different distributed antenna system at the same time. These CCLS are a part of hybrid systems that transmit radio frequency energy by conduction over the communication media received by conduction and radiation infrastructure which are easily installed cellular over fiber solutions for WCDMA/LTE access that is becoming Ubiquitous Network to IOT real case hierarchy of telecommunication.
Future studies will include comparison of DAS and Femtocells in indoors, as well as network planning with indoor CDMA2000, WCDMA, and LTE at the same time to reduce the number of the eNode $B$ implementation for high levels building and metro rapid transit system.

\section{Conflict of Interests}

The authors declare that there is no conflict of interests regarding the publication of this paper.

\section{References}

[1] B. J. Koshy and P. M. Shankar, "Spread-spectrum techniques for fiber-fed microcellular networks," IEEE Transactions on Vehicular Technology, vol. 48, no. 3, pp. 847-857, 1999.

[2] M. V. S. N. Prasad and R. Singh, "Terrestrial mobile communication train measurements in Western India," IEEE Transactions on Vehicular Technology, vol. 52, no. 3, pp. 671-682, 2003.

[3] Y. P. Zhang, "Practical performance of digital cellular system in mass rapid transit environments," International Journal of Communication Systems, vol. 18, no. 2, pp. 143-157, 2005.

[4] H. A. Raweshidy and S. Komaki, Radio over Fiber Technologies for Mobile Communications Networks, Artech House, 2002.

[5] S. Hwang, H. Kim, B. Kim et al., "RoF technologies for inbuilding wireless systems," IEICE Transactions on Electronics, vol. 90, no. 2, pp. 345-350, 2007.

[6] Andrew Company, ION-M85/18/21 System Overview, Worldwide Headquarters 3 Westbrook Corporate Center Suite, Westchester, Ill, USA, 2013.

[7] 3GPP TS 25.143-V 6.4.0, "Radio Access Network UTRA Repeater Conformance Testing," Release 6, 2006.

[8] Andrew Company, ION-M85/18/21 Design Principle, Andrew Company, Westchester, Ill, USA, 2013. 
[9] T. S. Rappaport, Wireless Communication Principles and Practice, vol. 2, Prentice Hall PTR, Upper Saddle River, NJ, USA, 1996.

[10] J. W. Goodman, Introduction to Fourier Optics, Roberts \& Company Publishers, Greenwood Village, Colo, USA, 3rd edition, 2004.

[11] D. Didascalou, J. Maurer, and W. Wiesbeck, "Subway tunnel guided electromagnetic wave propagation at mobile communications frequencies," IEEE Transactions on Antennas and Propagation, vol. 49, no. 11, pp. 1590-1596, 2001.

[12] S. F. Su, The UMTS Air-Interface in RF Engineering: Design and Operation of UMTS Networks, McGraw-Hill, New York, NY, USA, 2007.

[13] M. Lienard and P. Degauque, "Propagation in wide tunnels at 2 GHz: a statistical analysis," IEEE Transactions on Vehicular Technology, vol. 47, no. 4, pp. 1322-1328, 1998.

[14] P. Mariage, M. Lienard, and P. Degauque, "Theoretical and experimental approach of the propagation of high frequency waves in road tunnels," IEEE Transactions on Antennas and Propagation, vol. 42, no. 1, pp. 75-81, 1994.

[15] C. L. Holloway, D. A. Hill, R. A. Dalke, and G. A. Hufford, "Radio wave propagation characteristics in lossy circular waveguides such as tunnels, mine shafts, and boreholes," IEEE Transactions on Antennas and Propagation, vol. 48, no. 9, pp. 13541366, 2000.

[16] C. H. Cox, Analog Optical Links Theory and Practice, Cambridge University Press, Cambridge, UK, 2006.

[17] Ericsson Review, Signal Strength Measurement in GSM/ CDMA2000/WCDMA TEMS Mobiles, Ericsson TEMS AB, Taipei, Taiwan, 2013.

[18] 3rd Generation Partnership Project, "Radio Access Network UTRA repeater radio transmission and reception-release 6," 3GPP TS 25.106, V 6.4.0, 2006.

[19] T. Isotalo, J. Niemela, and J. Lempiainen, "Measurements for distributed antennas in WCDMA indoor network," in Proceedings of International Symposium of Wireless Personal Multimedia Communications (WPMC '06), pp. 17-20, 2006. 


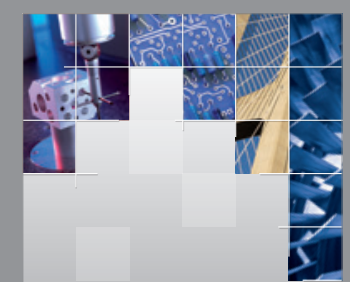

\section{Enfincering}
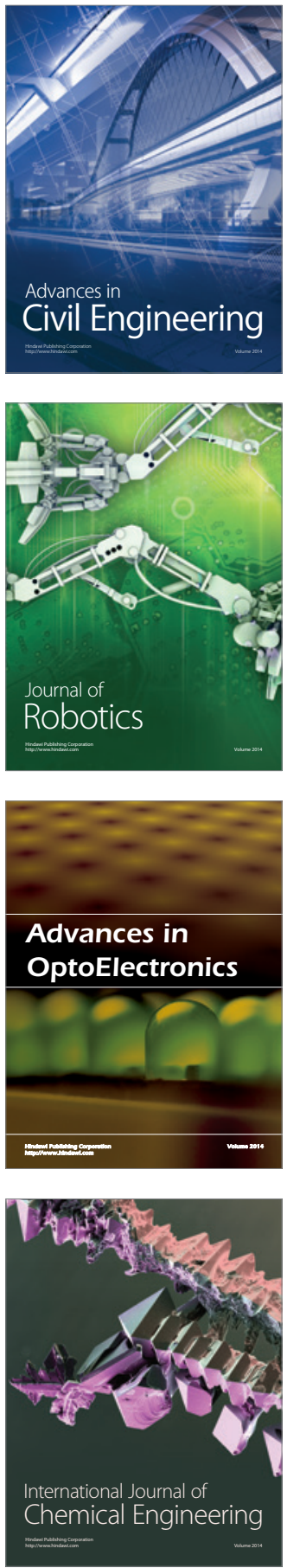

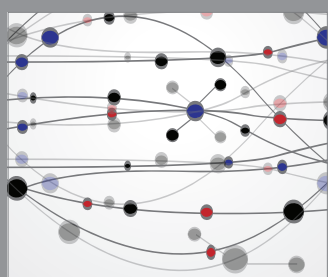

The Scientific World Journal

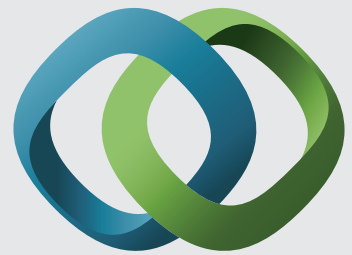

\section{Hindawi}

Submit your manuscripts at

http://www.hindawi.com
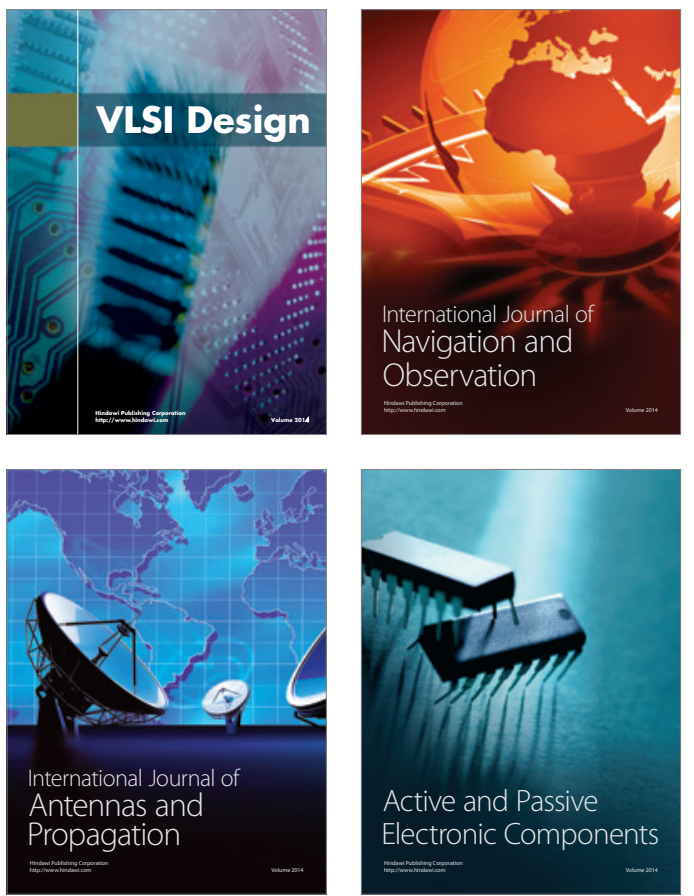
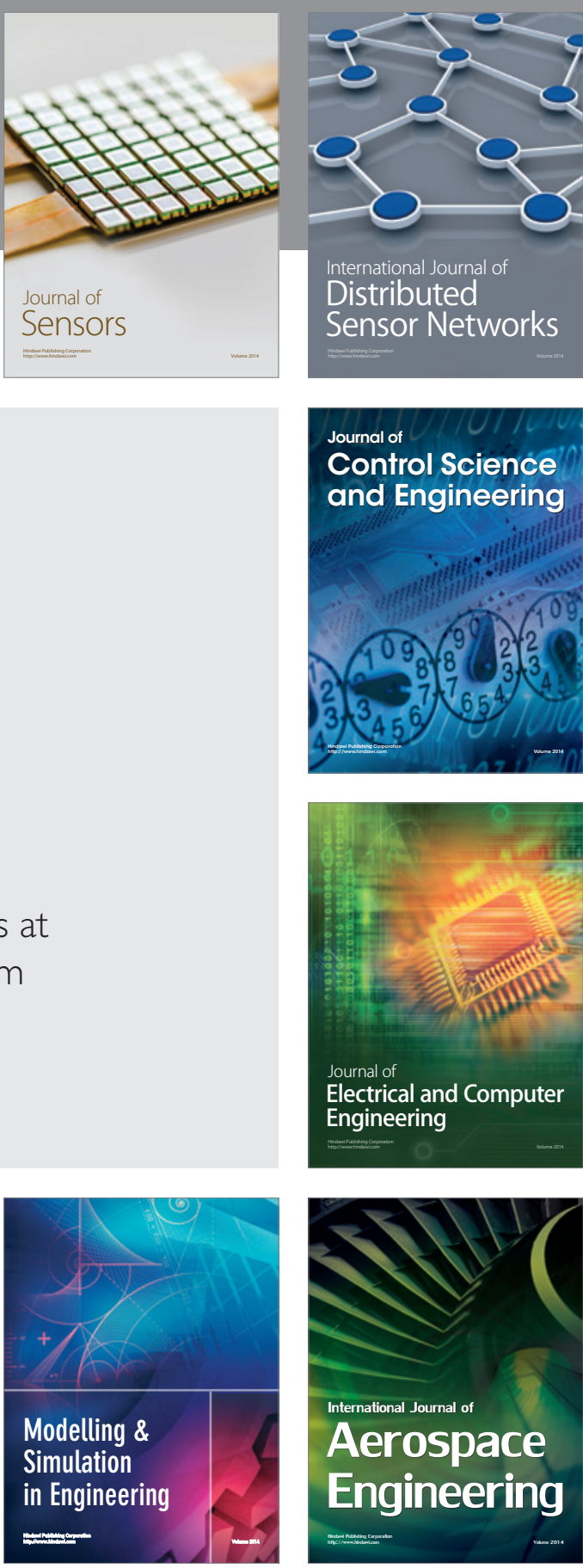

International Journal of

Distributed

Sensor Networks

Journal of

Control Science

and Engineering
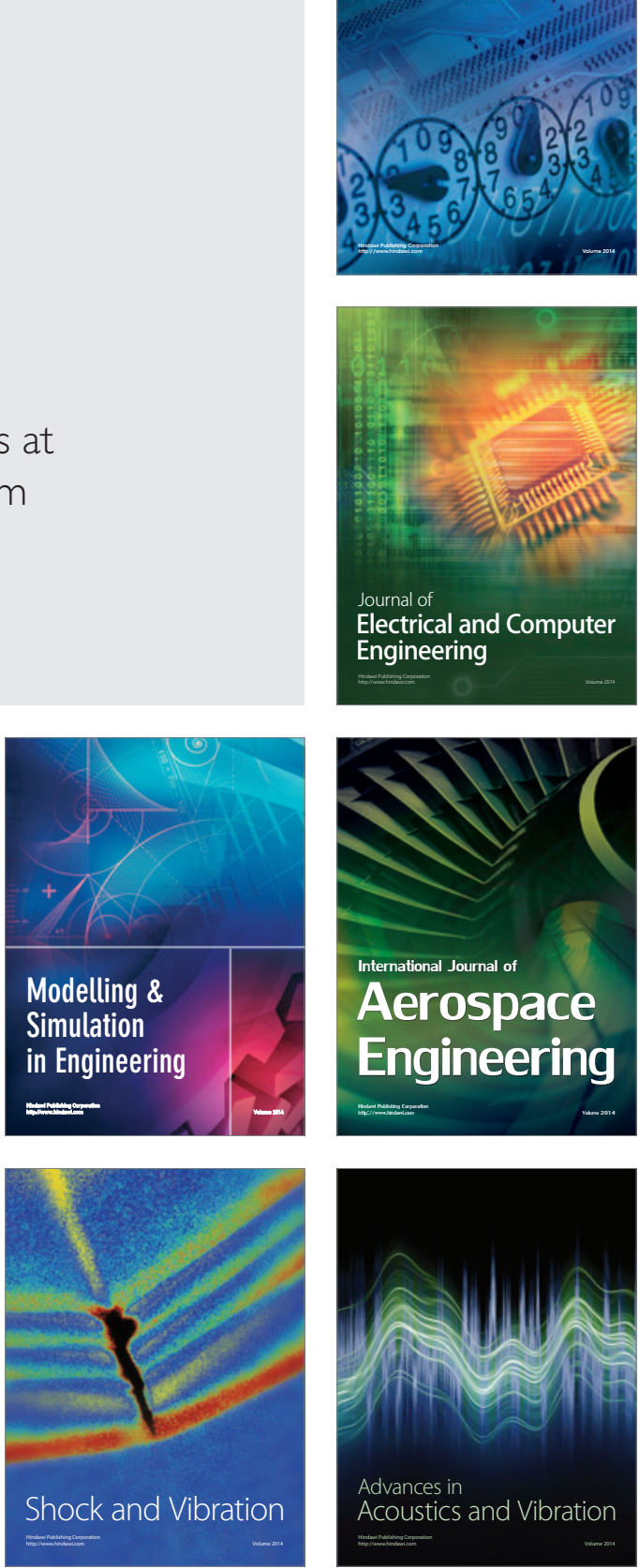